Augmentation of Stagnation Region Heat Transfer Due to Turbulence From a DLN Can Combustor

\author{
G. James Van Fossen
}

Glenn Research Center, Cleveland, Ohio

Ronald S. Bunker

General Electric, Schenectady, New York 
Since its founding, NASA has been dedicated to the advancement of aeronautics and space science. The NASA Scientific and Technical Information (STI) Program Office plays a key part in helping NASA maintain this important role.

The NASA STI Program Office is operated by Langley Research Center, the Lead Center for NASA's scientific and technical information. The NASA STI Program Office provides access to the NASA STI Database, the largest collection of aeronautical and space science STI in the world. The Program Office is also NASA's institutional mechanism for disseminating the results of its research and development activities. These results are published by NASA in the NASA STI Report Series, which includes the following report types:

- TECHNICAL PUBLICATION. Reports of completed research or a major significant phase of research that present the results of NASA programs and include extensive data or theoretical analysis. Includes compilations of significant scientific and technical data and information deemed to be of continuing reference value. NASA's counterpart of peerreviewed formal professional papers but has less stringent limitations on manuscript length and extent of graphic presentations.

- TECHNICAL MEMORANDUM. Scientific and technical findings that are preliminary or of specialized interest, e.g., quick release reports, working papers, and bibliographies that contain minimal annotation. Does not contain extensive analysis.

- CONTRACTOR REPORT. Scientific and technical findings by NASA-sponsored contractors and grantees.
- CONFERENCE PUBLICATION. Collected papers from scientific and technical conferences, symposia, seminars, or other meetings sponsored or cosponsored by NASA.

- SPECIAL PUBLICATION. Scientific, technical, or historical information from NASA programs, projects, and missions, often concerned with subjects having substantial public interest.

- TECHNICAL TRANSLATION. Englishlanguage translations of foreign scientific and technical material pertinent to NASA's mission.

Specialized services that complement the STI Program Office's diverse offerings include creating custom thesauri, building customized data bases, organizing and publishing research results ... even providing videos.

For more information about the NASA STI Program Office, see the following:

- Access the NASA STI Program Home Page at $h t t p: / / w w w . s t i . n a s a . g o v$

- E-mail your question via the Internet to help@sti.nasa.gov

- Fax your question to the NASA Access Help Desk at (301) 621-0134

- Telephone the NASA Access Help Desk at (301) 621-0390

- Write to: NASA Access Help Desk NASA Center for AeroSpace Information 7121 Standard Drive Hanover, MD 21076 
NASA/TM-2000-210241

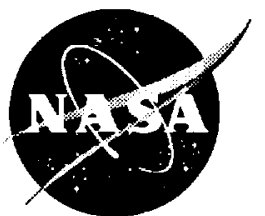

\section{Augmentation of Stagnation Region Heat Transfer Due to Turbulence From a DLN Can Combustor}

G. James Van Fossen

Glenn Research Center, Cleveland, Ohio

Ronald S. Bunker

General Electric, Schenectady, New York

Prepared for the 45th International Gas Turbine and Aeroengine Technical Congress sponsored by the American Society of Mechanical Engineers Munich, Germany, May 8-11, 2000

National Aeronautics and Space Administration

Glenn Research Center 
Available from

NASA Center for Aerospace Information 7121 Standard Drive

Hanover, MD 21076

Price Code: A03
National Technical Information Service 5285 Port Royal Road Springfield, VA 22100 Price Code: A03 


\title{
AUGMENTATION OF STAGNATION REGION HEAT TRANSFER DUE TO TURBULENCE FROM A DLN CAN COMBUSTOR
}

\author{
G. James Van Fossen \\ National Aeronautics and Space Administration \\ Glenn Research Center \\ Cleveland, Ohio \\ Ronald S. Bunker \\ General Electric \\ Schenectady, New York
}

\section{ABSTRACT}

Heat transfer measurements have been made in the stagnation region of a flat plate with a circular leading edge. Electrically heated aluminum strips placed symmetrically about the leading edge stagnation region were used to measure spanwise averaged heat transfer coefficients. The maximum Reynolds number obtained, based on leading edge diameter, was about 100,000 . The model was immersed in the flow field downstream of an approximately half scale model of a can-type combustor from a low $\mathrm{NO}_{\mathrm{x}}$, ground based power-generating turbine. The tests were conducted with room temperature air; no fuel was added. Room air flowed into the combustor through six vane type fuel/air swirlers. The combustor can contained no dilution holes.

The fuel/air swirlers all swirled the incoming airflow in a counter clockwise direction (facing downstream). A 5-hole probe flow field survey in the plane of the model stagnation point showed the flow was one big vortex with flow angles up to $36^{\circ}$ at the outer edges of the rectangular test section. Hot wire measurements showed test section flow had very high levels of turbulence, around $28.5 \%$, and had a relatively large axial-length scale-to-leading edge diameter ratio of 0.5 . X-wire measurements showed the turbulence to be nearly isotropic. Stagnation heat transfer augmentation over laminar levels was around $77 \%$ and was about $14 \%$ higher than predicted by a previously developed correlation for isotropic grid generated turbulence.

\section{NOMENCLATURE}

$B \quad$ wind tunnel blockage

$C_{\tau} \quad$ constant in fit of autocorrelation, sec. $^{-1}$

$d \quad$ leading edge diameter, $\mathrm{cm}$

$E \quad$ hot wire bridge voltage, volts

$e \quad$ fluctuating component of bridge voltage, volts

Fr Frossling number $=$ Nusselt $/(\operatorname{Re})^{1 / 2}$

Pr Prandtl number

$R \quad$ radius of model leading edge, $\mathrm{cm}$

$r$ recovery factor

\author{
$R(\tau)$ autocorrelation function \\ Re Reynolds number \\ $s \quad$ surface distance from stagnation point, $\mathrm{cm}$ \\ $T$ temperature, $\mathrm{K}$ \\ Tu turbulence intensity \\ $U, V$ axial and cross-stream components of velocity, \\ $\mathrm{m} / \mathrm{sec}$ \\ $u^{\prime}, v^{\prime}$ fluctuation components of $\mathrm{U} \& \mathrm{~V}, \mathrm{~m} / \mathrm{sec}$
}

$$
\begin{array}{ll}
\multicolumn{2}{c}{\text { Greek }} \\
\Lambda & \text { Length scale, } \mathrm{cm} \\
\kappa & \text { wave number, } \mathrm{m}^{-1} \\
\rho & \text { Density, } \mathrm{kg} / \mathrm{m}^{3} \\
\tau & \text { Delay time in autocorrelation, sec. }
\end{array}
$$

\section{Subscripts}

\begin{tabular}{ll}
\hline$a v g$ & averaged over time \\
$d$ & leading edge diameter \\
$R M S$ & root mean square \\
$r$ & recovery \\
$s t$ & static condition \\
$t$ & total condition \\
$x$ & axial direction \\
$\infty$ & free stream condition
\end{tabular}

\section{INTRODUCTION}

Firing temperatures of modern turbine engines often exceed the melting temperature of the downstream blade and vane alloy material thus requiring the hardware to be cooled by compressor discharge air or some other means. The design of these cooling systems requires a knowledge of the heat transfer coefficients between the hot gas and the blade or vane. Turbulence in the combustor exit stream plays a major role in determining the level of heat transfer. The stagnation region is an area of high heat transfer and is very sensitive to the level of freestream turbulence. The objective of the present work is to determine the level of stagnation region heat transfer augmentation due to turbulence produced by a scaled, can-type combustor from a ground-based, gas-fired, 
turbine operating at room temperature and compare the results with heat transfer augmentation from isotropic grid-generated turbulence.

It has been known for a long time that a small increase in freestream turbulence from laminar levels can cause a large increase in heat transfer from the stagnation region of a bluff body such as a turbine vane or blade, Zapp (1950), Giedt (1951). Early attempts at correlation, e.g. Smith \& Kuethe (1966) and Lowery \& Vachon (1975), ignored the effect of turbulent length scale and tried to correlate heat transfer augmentation with only turbulence intensity and Reynolds number. These attempts resulted in large, unexplained scatter when compared to the data of other researchers. The works of Ames (1994) and Van Fossen, et al. (1994) showed that length scale was also an important parameter.

Van Fossen, et al. (1994) studied the augmentation of stagnation region heat transfer due to isotropic turbulence from square-bar, square-mesh grids. A correlating parameter was developed from experimental data taken with several different grids which grouped the augmentation data very tightly, $( \pm 4 \%)$. The isotropic data of several other studies were compared to the correlation and found to agree within $\pm 10 \%$. Data from an array of parallel, fine wires that generated non-isotropic turbulence were correlated by the parameter but showed a much higher level of augmentation than the isotropic turbulence.

Ames (1994) fabricated turbulence generators that resembled a combustor liner having primary air inlets and dilution holes. Using the rapid distortion theory of Hunt and Graham (1978), he developed a correlating parameter based on intensity, Reynolds number and what he called an energy-scale, the average size of the energy containing eddies. The correlation fit his and other data quite well.

Results to be presented from the present work include heat transfer measurements in the stagnation region of a flat plate with a circular leading edge, a 5-hole probe flowfield survey, turbulence intensity survey using a single hot wire, and $\mathrm{X}$-wire results downstream of the simulated combustor liner.

\section{TEST FACILITY, INSTRUMENTATION AND DATA ACQUISITION}

Wind Tunnel-The experiments were carried out in the wind tunnel shown in Fig. 1.

Air drawn from the test cell passed through the six-scaled combustor fuel/air swirlers into the $32.4-\mathrm{cm}$ diameter by $26.4-\mathrm{cm}$ long can, through a constant area, $68.5-\mathrm{cm}$ long, transition section and into the $15.2-\mathrm{cm}$ by $54.1-\mathrm{cm}$ by $77.5-\mathrm{cm}$ long test section. Air leaving the test section then passed through another transition section to a 10-inch pipe, which contained an orifice for flow measurement and a butterfly valve for flow control. Flow through the swirlers could be choked so the control valve was set to supply the maximum test section pressure that gave the maximum flow rate. The ratio of test section static pressure to test cell barometric pressure was typically 0.63 . This gave a leading edge Reynolds number of about 100,000 . A Kiel probe located in the test section was used to measure the total pressure for each run. Four chromel-alumel thermocouples near the inlet of the swirlers measured the total inlet temperature. A 2dimensional actuator system allowed hot wire and 5hole probe surveys in a plane perpendicular to the flow that passed through the stagnation line of the heat transfer model. The model was not present when the flow surveys were conducted.

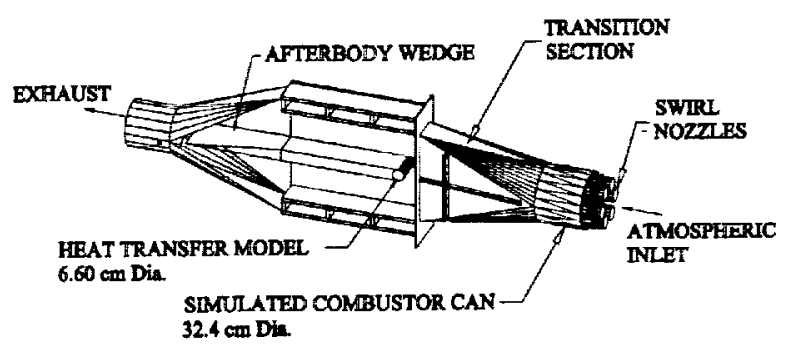

Figure 1.-Rig layout.

Simulated Combustor-The combustor liner model is of the natural gas fired, Dry-Low-NOx (DLN), can-type having no dilution or film cooling air injection. Six identical, scaled DLN-type fuel-air swirlers are set into the upstream end, or headend, of the combustor liner. Each swirler, shown in fig. 2, was composed of a set of 12 large air swirl vanes (outer) and a 16-vane diffusion gas tip (inner).

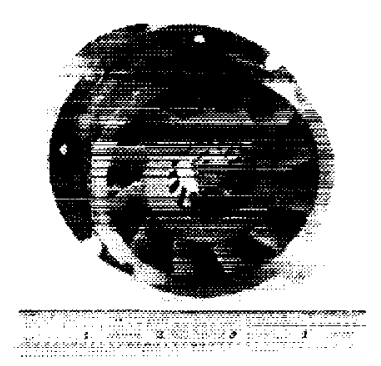

Figure 2.-DLN fuel-air swirler looking upstream.

The air swirler vane sets were cast stainless steel with about 45-degrees of turning. The diffusion gas tips were fabricated from aluminum for this mockup. Swirl is in the same direction for each of the inner and outer vanes. Each swirler is also provided with a hardware. In this mockup, the headend has no additional flow orifices other than the swirlers. This configuration results in a cold flow combustor 
mockup, generating both swirl and large-scale turbulence typical of a land-based power turbine. While this cold flow combustor mockup does not achieve the pressure and temperature levels of an actual engine, nor does it have the reaction and combustion chemistry, previous work of Zimmerman (1979) and Geobel et al. (1993) indicates that the inclusion of the major geometry and flow features in such a cold flow device does result in the generation of freestream turbulence and swirl representative of a pressurized and fired system.

Five Hole Pressure Probe-Mean flow angle and velocity were measured with a standard, commercially available, 5-hole pressure probe. Pressures were measured with strain gage type transducers and recorded using the Laboratory steady state data recording system.

Hot wire instrumentation-Turbulence measurements were obtained using a 2-channel constant temperature anemometer system. The turbulence intensity survey in the plane of the model stagnation point was conducted with a single hot wire oriented parallel to the model spanwise direction with the model removed. Bridge voltage was converted to mean and RMS components with special purpose analog meters whose output was recorded with the Laboratory steady state data acquisition system. Length scale and isotropy measurements were made with a cross-flow $\mathrm{X}$-wire probe. The wires were oriented perpendicular to the model spanwise direction. Bridge voltage was passed through an 8 pole, 6 zero, constant delay antialiasing filter set to begin roll off at $6 \mathrm{kHz} .2^{20}$ samples were recorded at an $18 \mathrm{kHz}$ sampling frequency with a high-speed, 12-bit, digital to analog conversion (DAC) board and stored in a personal computer. In order to obtain good resolution of the fluctuating component of the signal it was necessary to subtract a known DC voltage from the raw signal then amplify the result before passing it to the DAC. For all hot wire measurements the frequency response was estimated to be about $90 \mathrm{kHz}$ using the standard square wave test.

Heat Transfer Model--The heat transfer model was a $65-\mathrm{cm}$ long flat plate with a circular leading edge with a radius of $3.30-\mathrm{cm}$. The model spanned the $15.2-\mathrm{cm}$ test section width. A $52-\mathrm{cm}$ long wedge shaped afterbody designed to eliminate vortex shedding extended downstream into the outlet transition section as shown in Fig. 1. The model contained 19 heat flux gages consisting of aluminum strips $6.6-\mathrm{cm}$ long by $0.48-\mathrm{cm}$ wide and $0.32-\mathrm{cm}$ deep with a thin foil electric heater glued to the rear and a chromel-alumel thermocouple embedded in a groove.
Each gage averaged the heat transfer over its $6.6-\mathrm{cm}$ span. The farthest downstream gages were used as guard heaters to minimize losses in the streamwise direction. A guard heater behind the gages prevented conduction to the interior of the model. The average gap between the aluminum strips was $0.25 \mathrm{~mm}$ and was filled with epoxy. The aluminum strips were maintained at a constant temperature $\left( \pm 0.25^{\circ} \mathrm{C}\right)$ by a specially designed control circuit (Van Fossen et al. 1984).

\section{DATA REDUCTION}

Flow Field-The 5-hole probe was calibrated in an atmospheric jet over a range of pitch and yaw angles using the technique described in Giel et al. (1996). Yaw and pitch angles were least square curve fit with fourth order polynomials. Symmetry was not assumed in any of the curve fits.

\section{Turbulence}

Intensity-Hot wire probes were calibrated in an atmospheric jet. A fourth order polynomial was used to fit bridge voltage versus density-velocity product. Density-velocity product was used because the test section pressures were below atmospheric thus calibration density was different than test section density. The mean and RMS voltages recorded for the intensity survey with the steady state recording system were converted to density velocity product and turbulence intensity was calculated as

$$
T u=\frac{\left[\frac{d(\rho U)}{d E}\right]_{E} e_{R M S}}{\rho U}
$$

Where $E$ is the bridge voltage, $\mathrm{e}_{R M S}$ is the RMS component of the bridge voltage and the derivative is the slope of the calibration curve at $E$.

Integral Length Scale-Length scale was calculated from the autocorrelation function by fitting an exponential curve

$$
R(\tau)=e^{-C_{\mathrm{r}} \tau}
$$

between the arbitrary limits of $\mathrm{I}>\mathrm{R}(\mathrm{t})>0.33$. Integrating $R(t)$ between zero and infinity and multiplying by the mean velocity gives the integral length scale,

$$
\Lambda_{x}=U \int_{0}^{\infty} R(t) d t=\frac{U}{C_{\tau}}
$$


Although not a problem with this data set, this method of computing the length scale eliminates inconsistent results from some data which contain low frequency noise, see Van Fossen et al. (1994).

Isotropy-The X-wire probe was calibrated in the same air jet used to calibrate the single wire probe. The procedure was to set the probe angle so both wires were as close as possible $45^{\circ}$ to the flow and perform a velocity calibration as was done for the single wire. This produced a curve fit of bridge voltage versus jet velocity for each wire. A directional calibration was accomplished by setting the jet density-velocity product at the value expected in the test section and recording bridge voltage versus jet velocity over a range of probe angles between $-40^{\circ}$ and $+40^{\circ}$. Using the velocity curve fit for each wire, a density-velocity product was calculated for each probe angle and normalized by the actual jet density-velocity product. These data sets were then curve fit with polynomials. Figure 3 shows the resulting calibration curves with the data points superimposed.

It can be seen in the directional calibration that wire 2 , the outer wire, looks like a cosine curvenormal behavior for an angled hot wire. Wire 1 however looks like the cosine for angles between $-40^{\circ}$ and $0^{\circ}$ but at angles greater than $0^{\circ}$ does not. This is a problem inherent to the cross-flow probe design; at angles greater than $0^{\circ}$ wire 1 is in the wake of the prongs that support wire 2 . Several features of this type of probe outweigh this inconvenience: 1) the wire angle can be changed by simply rotating the probe stem without a change in the streamwise or crossstream position, 2) the probe can be inserted through a small $(6.4-\mathrm{mm})$ hole in an actuator or tunnel wall without having other access to the test section such as a window or door to install the probe tip. This shortcoming of the crossflow probe can be overcome by limiting the flow angles relative to the probe to the range $-40^{\circ}$ to $0^{\circ}$. The curve fits from fig. 3 were used to construct a lookup table of the ratio $\rho V_{1} / \rho V_{2}$ versus probe angle. The data reduction procedure was then: 1) calculate $\rho V_{1}$ and $\rho V_{2}$ using the curve fits of velocity versus bridge voltage. 2) using the ratio of $\rho V_{1} / \rho V_{2}$ and the lookup table, find the angle of the velocity vector relative to the probe, 3 ) using the curve fit of $\rho V_{2} / \rho V_{\text {jet }}$ versus angle, compute $\rho V_{\text {jet }}\left(\rho V_{\text {jet }}\right.$ is now the magnitude of the mass-velocity vector).

\section{Heat Transfer}

An energy balance was used to determine the Frossling number for each gage:

$$
F r(s / R)=\frac{\left(q_{E I}-q_{r a d}-q_{g a p}\right) d}{A\left[T_{W}-T_{r}(s)\right] k \sqrt{\operatorname{Re}_{d}}}
$$
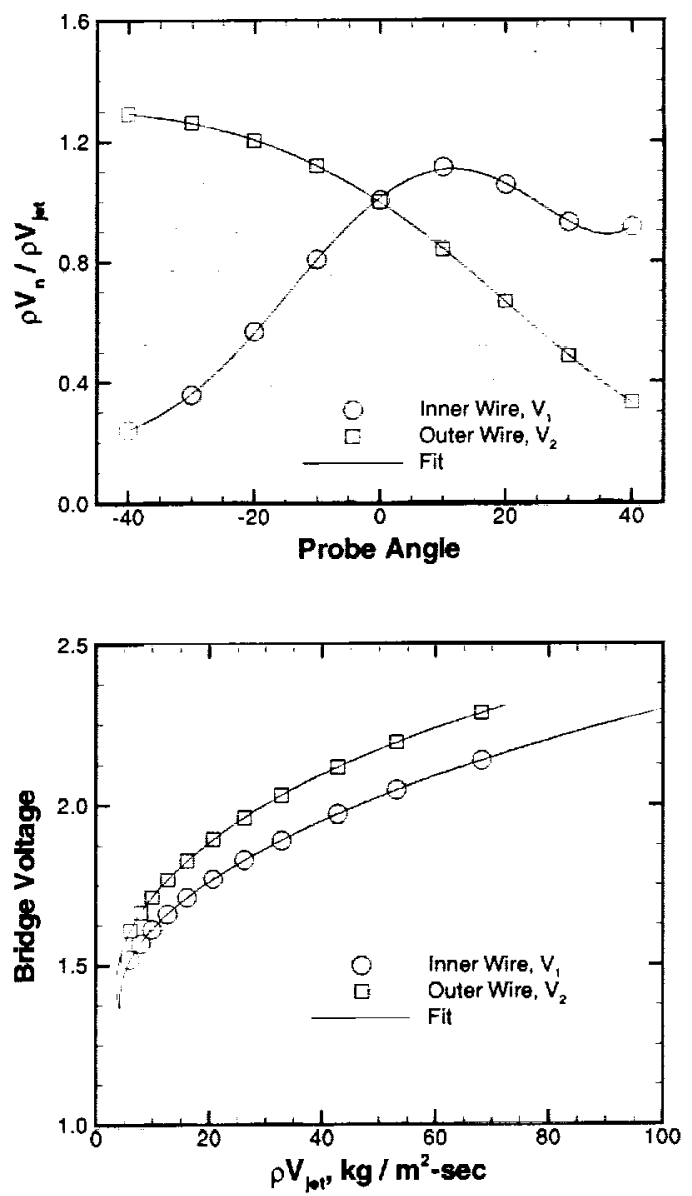

Figure 3-Cross-flow $\mathrm{X}$-wire calibration curves.

Where $q_{E I}$ is the heat added to the gage by the electric heater, $q_{r a d}$ is the heat lost by radiation, $q_{g a p}$ is the heat conducted away from the gage to the epoxy gap and the unguarded ends of the heaters, $A$ is the exposed gage surface area, $T_{w}$ is the gage temperature, $T_{r}(s)$ is the local recovery temperature, $k$ is the thermal conductivity of air, and $R e_{d}$ is the Reynolds number based on leading edge diameter, $d$. Corrections for radiation heat loss, $\mathrm{q}_{\mathrm{rad}}$, were made assuming gray body radiation to black surroundings and an emissivity of 0.05 for the aluminum gage.

An estimate of the gap loss, qgap, can be obtained from an exact solution for two-dimensional heat conduction in a rectangle. See Van Fossen, et al. (1984) for details. The gap loss was about 10 percent of the total heat flow while the radiation heat loss was on the order of 0.2 percent.

The recovery temperature was calculated as

$$
T_{r}(s)=T_{s t, \infty}+r(s)\left(T_{t}-T_{s t, \infty}\right)
$$

Where $T_{s t,:}$ is the static temperature upstream of the model. 
The local recovery factor, $r(s)$, was calculated as

$$
r(s)=1-\left(\frac{\rho U(s)}{(\rho U)_{\infty}}\right)^{2}(1-\sqrt{\operatorname{Pr}})
$$

The local mass flow ratio, $\rho U(s) /(\rho U)$, was found from a numerical solution of flow over the model that included the tunnel walls (Rigby et al., 1992).

Following the results of Rigby et al. (1992), the thermal conductivity and viscosity of air were evaluated at the free-stream total temperature from equations given in Hillsenrath et al. (1955).

The Reynolds number, $R e_{d}$, was based on the diameter of the leading edge, $d$, and the mass-velocity averaged between the flow area with maximum model blockage and the unblocked flow area, that is,

$$
(\rho U)_{a v g}=(\rho U)_{\infty} \frac{(2-B)}{2(1-B)}
$$

Where the blockage, $B$, is the ratio of maximum model thickness to tunnel height. Blockage was 0.122 for this test.

\section{UNCERTAINTY ANALYSIS}

Frossling number-Estimates of the bias error of each measuring instrument were made and combined by the method of Kline and McClintock (1953). Estimates of the precision of each measurement were calculated from 20 samples of each steady-state measurement and combined by the same method. The maximum Frossling number uncertainty occurred at the stagnation gage and was $5.7 \%$.

Flowfield measurements-Estimates of error in the hot wire and 5-hole probe measurements were made using a method suggested by Yavuzkurt (1984). Estimated error in turbulence intensity was $12.9 \%$ and in length scale was $18.3 \%$.

\section{RESULTS AND DISCUSSION}

Flow Field-Results of the 5-hole probe survey are shown in fig. 4. Shown on the figure are streamlines and vectors that represent the components of velocity perpendicular to the axial direction. The length of the vector at the top of the figure is representative of the magnitude of the axial velocity. It can be seen that vortices from the six individual swirl nozzles add together to form a single vortex at the inlet to the test section. The center of the vortex is displaced from the tunnel centerline. Flow angles of up to $36^{\circ}$ were measured at the extreme spanwise positions and angles near $0^{\circ}$ were recorded at midspan.

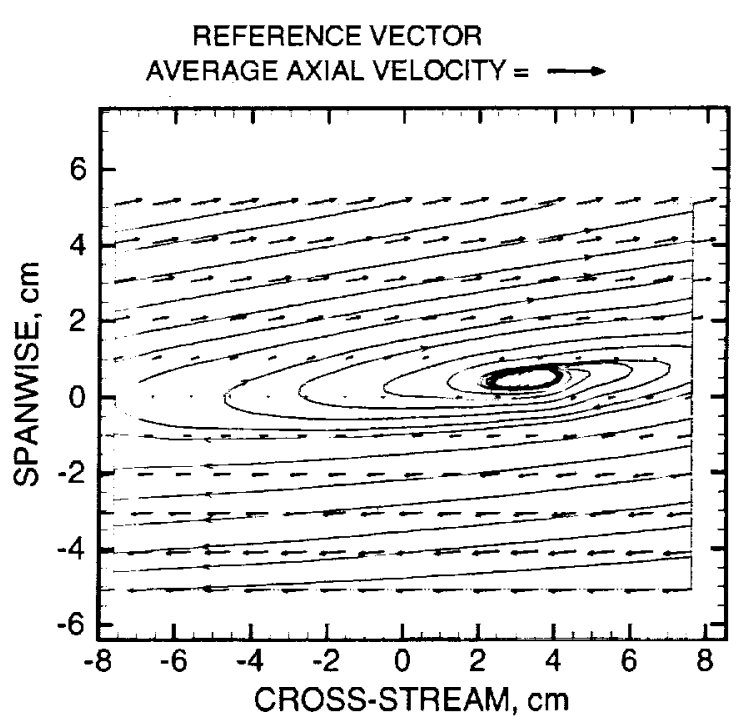

Figure 4.-Five-hole probe survey; cross-stream vector and streamline plot.

Figure 5 shows the mean flow velocity components in the axial and cross-stream directions measured with the $\mathrm{X}$-wire.

The axial component varies about $17 \%$ in the spanwise direction with a minimum near mid-span. The cross-stream component varies linearly with span with zero velocity corresponding with the mid-span position.

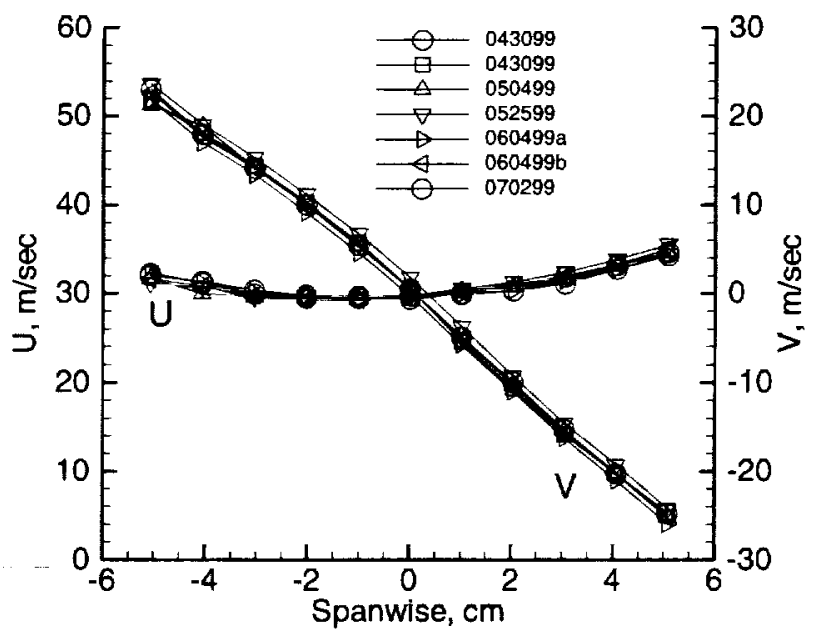

Figure 5.-X-wire traverse: mean axial flow and cross-stream velocity components. 
Turbulence-A survey of turbulence intensity measured with the single hot wire is shown in fig. 6 . Intensity was stratified in the spanwise direction with a maximum of around $30 \%$ at mid-span and tapering off to around $21 \%$ at the full test section span. Intensity averaged over the span of the stagnation heat transfer gage was $28.5 \%$.

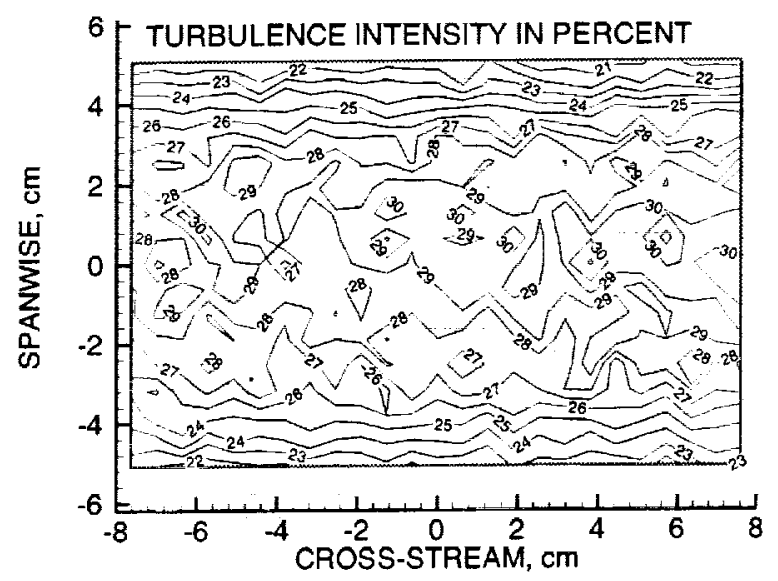

Figure 6.-Turbulence intensity contour plot.

Figure 7 gives the fluctuating components of axial and cross-stream velocity. The axial component is nearly constant while the cross-stream component has a dip near mid-span. This, at first, appears contrary to the results of the single wire survey but closer examination shows that it is consistent. The single wire was oriented in the spanwise direction and thus would respond to axial and cross-stream components as:

$$
T u=\sqrt{\frac{\left(u^{\prime 2}+v^{\prime 2}\right)}{\left(U^{2}+V^{2}\right)}}
$$

The zero velocity of the cross-stream mean component, $V$, causes the intensity to peak in the center of the span.

Figure 8 shows the ratio of the two fluctuating velocities, $u^{\prime} / v^{\prime}$. The average ratio over the span is equal to 0.97 and varies only about $\pm 10 \%$ indicating that the flow is nearly isotropic.

Typical autocorrelation functions used to determine the length scale are shown in fig. 9. Also shown on the figure are the exponential curve fits used to determine the length scale. These figures are typical of autocorrelations for all the data taken. The axial direction autocorrelation is closely approximated by the exponential curve fit while the cross-stream component has a large area of negative correlation.

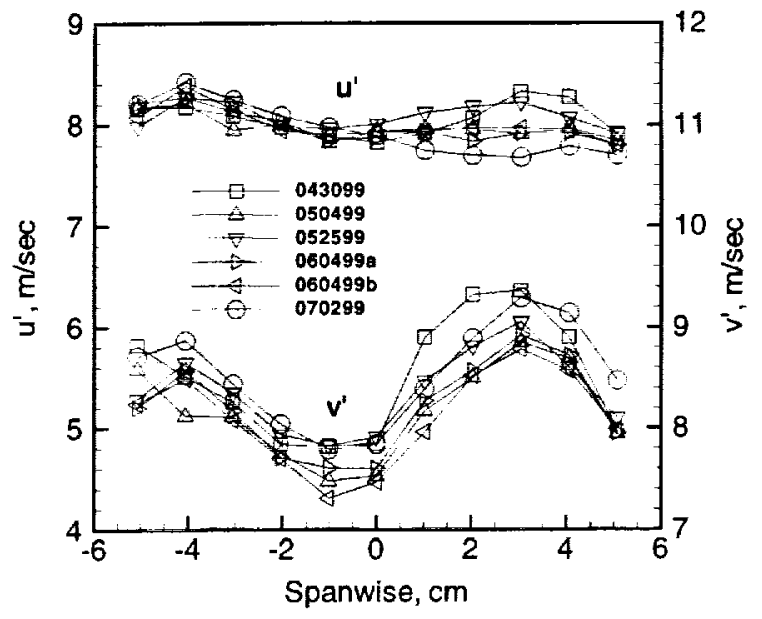

Figure 7.-X-wire traverse: RMS fluctuating axial and cross-stream velocity components.

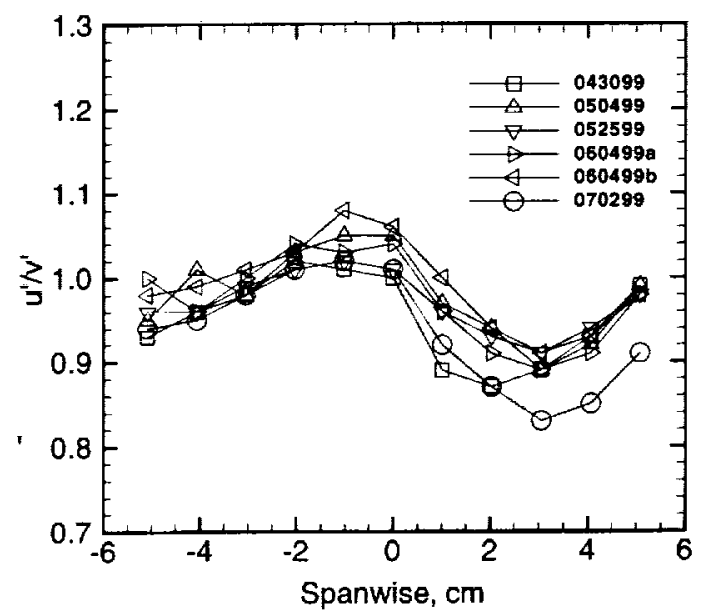

Figure 8. X-wire traverse: ratio of RMS fluctuating axial and cross-stream velocity components.

The spanwise distribution of length scale is shown on fig. 10. The average axial length scale was $3.34-\mathrm{cm}$ while the cross-stream length scale was $2.64-\mathrm{cm}$. making the ratio of axial to cross-stream length scale about 1.26 .

Axial and cross-stream components of the power spectrum in wave number space are shown in fig. 11 . Both components exhibit the $-5 / 3$ slope indicative of the inertial subrange. The rolloff in the spectrum at wave numbers greater than about 1500 is caused by the anti-aliasing filter. The spectra shown in fig. 11 are typical of all spanwise locations. 


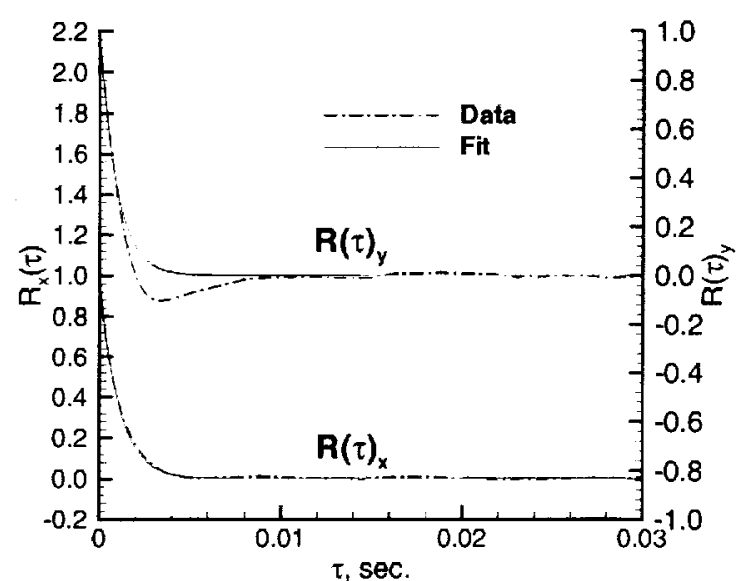

Figure 9.-Typical axial and cross-stream autocorrelation functions with curve fits.

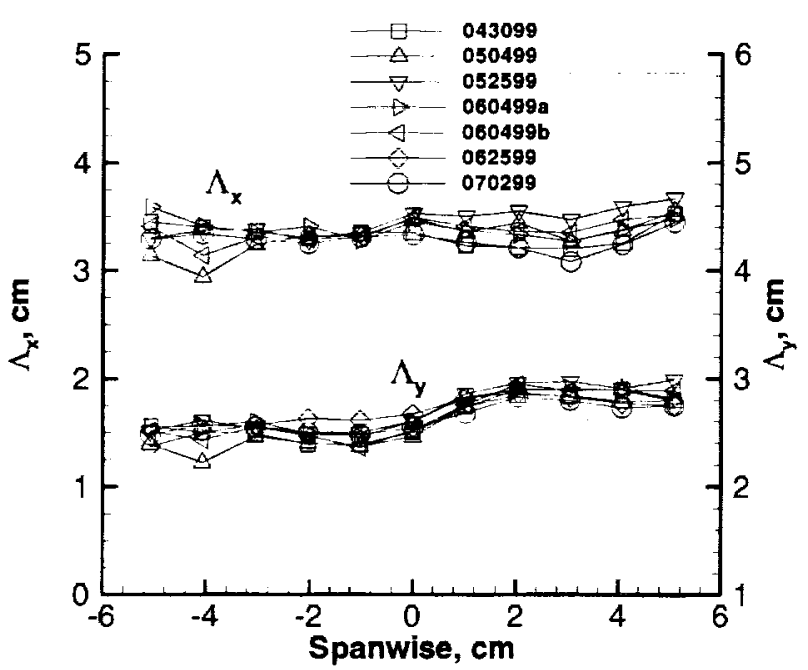

Figure 10.-X-wire traverse: axial ancd cross-stream length scales.

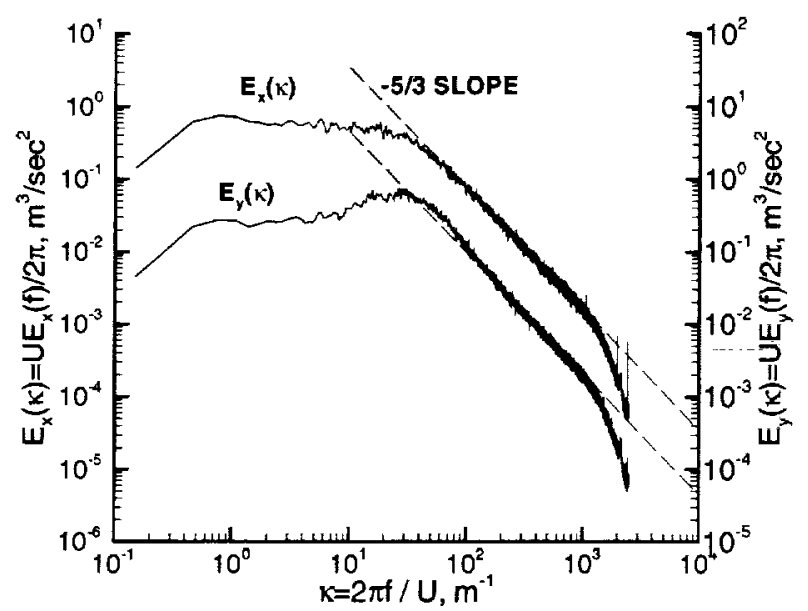

Figure 11.-Typical axial and cross-stream wave number spectrum.
Heat Transfer-The heat transfer distribution in the stagnation region is shown in fig. 12 where Frossling number (Nusselt number/ $\left(\mathrm{Re}_{\mathrm{d}}\right)^{1 / 2}$ ) is plotted versus the ratio of surface distance to leading edge radius. For comparison, a numerical solution for the cylindrical leading edge for a laminar free stream obtained using the PARC-2D code taken from Rigby and Van Fossen (1992) is shown.

Also shown are the PARC-2D code results multiplied by the factor 1.77 in order to match the experimental data at the stagnation point. The augmentation of stagnation heat transfer due to the DLN turbulence is about $77 \%$ above the laminar case. Frossling numbers for heat flux gages off the stagnation line generally follow the laminar distribution multiplied by the augmentation factor until $s / R$ of roughly $\pm 0.9\left(\sim 52^{\circ}\right)$. Beyond this value of $s / R$, the augmentation is greater than the 1.77 of the stagnation region.

Figure 13 shows a comparison of the DNL turbulence augmented stagnation heat transfer compared with a correlation for stagnation region heat transfer taken from Van Fossen et al. (1995).

The stagnation heat transfer due to the DLN turbulence is about $14 \%$ higher than the correlation predicts. The correlation was derived using turbulence generated with square-bar, square-mesh grids that produced nearly isotropic turbulence; the data was all contained within the $\pm 4 \%$ bands shown in fig. 13. Van Fossen et al. (1995) showed that non-isotropic turbulence could produce augmentation levels higher than that of isotropic turbulence. It was suspected that this was the cause of the increased augmentation by the DLN combustor turbulence but the turbulence measurements show that this is not the case; the DLN turbulence in nearly isotropic. The cause of this increased augmentation above isotropic grid turbulence levels remains unknown. One possibility could be the swirl in the mean flow causing an effective angle of attack on the leading edge: positive on one half of the span and negative on the other half. This has not been investigated. 


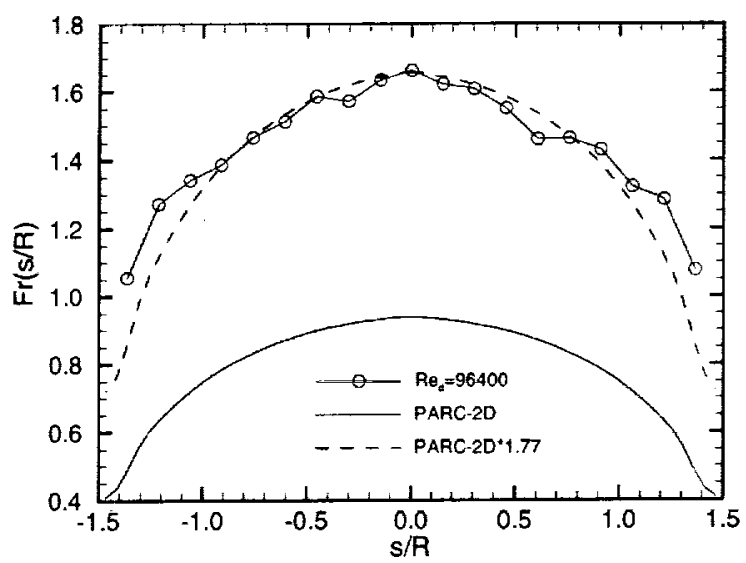

Figure 12.- Heat transfer distribution over the model leading edge.

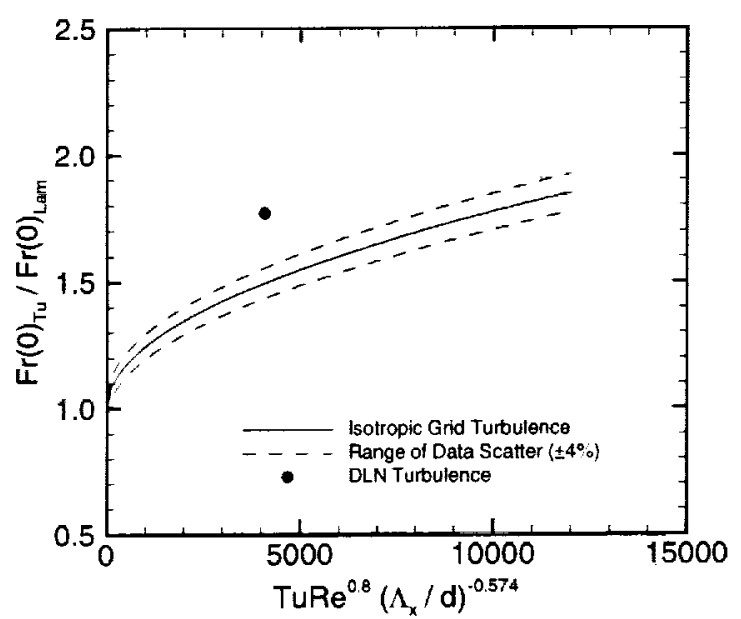

Figure 13.-Comparison of stagnation heat transfer augmentation due to DLN turbulence and correlation derived from square bar grid data.

\section{CONCLUSIONS}

Spanwise averaged heat transfer measurements were made in the stagnation region of a flat plate with a $3.3-\mathrm{cm}$ radius circular leading edge. The heat transfer model was placed downstream of a scaled, simulated, gas fired, combustor liner from a ground based, power turbine. Conclusions drawn from this study are:

1. The DLN combustor used in the present test with the swirl vanes from each of the six nozzles oriented in the same direction produced a single large swirl entering the test section. Flow angles up to $36^{\circ}$ from axial were recorded at the outer edge while flow angles of nearly zero were found at the center.

2. Very high levels of free stream turbulence were generated. Spanwise averaged turbulence intensity was found to be $28.5 \%$.
3. The turbulence generated appeared to be isotropic. Fluctuating components of velocity in the axial and cross-stream direction were nearly identical in magnitude. Wave number spectrum for both components demonstrated the -5/3-slope characteristic of an inertial subrange.

4. Average length scale in the axial direction was found to be $3.34-\mathrm{cm}$ while the crossstream direction length scale was $2.64-\mathrm{cm}$.

5. Stagnation heat transfer in the turbulent exhaust of the DLN combustor liner was found to be higher than that for a laminar free stream by a factor of 1.77 .

6. Stagnation heat transfer augmentation was found to be $14 \%$ higher than predicted by a correlation developed from isotropic grid generated turbulence.

\section{REFERENCES}

Ames, F.E. (1994), "Experimental Study of Vane Heat Transfer and Aerodynamics at Elevated levels of Turbulence," NASA CR-4633.

Giedt, W.H., (1951), "Effect of Turbulence Level of Incident Air Stream on Local Heat Transfer From Cylinders," J. of Aeronaut. Sci., vol. 18, no.11, pp. $725-730$.

Giel, P.W., Thurman, D.R., Lopez, I., Boyle, R.J., Van Fossen, G.J., (1966), "Three-Dimensional Flow Field Measurements in a Transonic Turbine Cascade," ASME Paper 96-GT-113.

Gobel, S., Abuaf, N., Lee, C.-P., (1993), "Measurements of Combustor Velocity and Turbulence Profiles," ASME Paper 93-GT-228.

Hillsenrath, J., Beckett, C.W., Benedict, W.S., Fano, L., and Hobe, H.J., (1955), "Tables of Thermal Properties of Gases," NBS Circular 564.

Hunt, J.C.R., and Graham, J.M.R., (1978), "FreeStream Turbulence Near Plane Boundaries," J.Fluid Mech., vol. 84, pp. 209-235.

Kline, S.J., and McClintock, F.A., (1953), "Describing Uncertainties in Single-Sample Experiments," Mech. Engineering, vol. 75 , pp. 3-8.

Lowery, G.W., and Vachon, R.I., (1975), "Effect of Turbulence on Heat Transfer From Heated Cylinders," Int. J. of Heat Mass Trans., vol, 18, no. 11, pp. 1229-1242. 
Rigby, D.L., Van Fossen, G.J., (1992), "Increased Heat Transfer to Elliptical Leading Edges Due to Spanwise Variations in the Freestream Momentum: Numerical and Experimental Results," AIAA paper 92-3070.

Smith, M.C., Kuethe, A.M., (1966), "Effects of Turbulence on Laminar Skin Friction and Heat Transfer," Phy. of Fluids, vol. 9, no. 12, pp. 23372344.

Van Fossen, G.J., Simoneau, R.J., Olsen, W.A., Shaw, R.J., (1984), "Heat Transfer Distributions Around Nominal Ice Accretion Shapes Formed on a Cylinder in the NASA Lewis Icing Research Tunnel," Presented at the AIAA $22^{\text {nd }}$ Aerospace Sciences Mtg., Jan. 9-12, Reno, NV (also NASA TM-83557).

Van Fossen, G.J., Simoneau, R.J., Ching, C.Y., (1994), "Influence of Turbulence Parameters, Reynolds Number, and Body Shape on Stagnation Region Heat Transfer, NASA TP-3487.
Van Fossen G.J., Simoneau, R.J., Ching, C.Y., (1995), "Influence of Turbulence Parameters, Reynolds Number, and Body Shape on Stagnation-Region Heat Transfer," J. of Heat Transfer, vol. 117, pp. 597-603.

Yavuskurt, S., (1984), "A Guide to Uncertainty Analysis of Hot-Wire Data," $J$. of Fluids Eng., vol. 106, pp. 181-186.

Zapp, G.M., (1950), "The Effect of Turbulence on Local Heat Transfer Coefficient Around a Cylinder Normal to an Air Stream," M.S. Thesis, Oregon State College, Corvalis, OR.

Zimmerman, D.R., (1979), "Laser Anemometer Measurements at the Exit of a T63-C20 Combustor," NASA CR-159623. 


\section{REPORT DOCUMENTATION PAGE}

Public reporting burden for this collection of information is estimated to average $\uparrow$ hour per response, including the time for revlewing instructions, searching existing data sources, gathering and maintaining the data needed, and completing and reviewing the collection of information. Send comments regarding this burden estimate or any ather aspect of this collection of information, including suggestions for reducing this burden, to Washington Headquarters Services, Directorate for Information Operations and Reports, 1215 Jefferson Davis Highway, Sulte 1204, Arlington, VA 22202-4302, and to the Oftice of Management and Budget. Paperwork Reduction Project (0704-0188), Washington, DC 20503.

\begin{tabular}{|l|l|l}
\hline 1. AGENCY USE ONLY (Leave blank) & $\begin{array}{c}\text { 2. REPORT DATE } \\
\text { July } 2000\end{array}$ & $\begin{array}{c}\text { 3. REPORT TYPE AND DATES COVERED } \\
\text { Technical Memorandum }\end{array}$
\end{tabular}

\section{TITLE AND SUBTITLE}

Augmentation of Stagnation Region Heat Transfer Due to Turbulence From a DLN Can Combustor

6. AUTHOR(S)

G. James Van Fossen and Ronald S. Bunker

7. PERFORMING ORGANIZATION NAME(S) AND ADDRESS(ES)

National Aeronautics and Space Administration

John H. Glenn Research Center at Lewis Field

Cleveland, Ohio 44135-3191

WU $-523-26-13-00$

5. FUNDING NUMBERS REPORT NUMBER

E-12360

9. SPONSORING/MONITORING AGENCY NAME(S) AND ADDRESS(ES)

10. SPONSORINGMONITORING AGENCY REPORT NUMBER

National Aeronautics and Space Administration

Washington, DC 20546-000I

NASA TM-2000-210241

ASME 2000-GT-0215

\section{SUPPLEMENTARY NOTES}

Prepared for the 45th International Gas Turbine and Aeroengine Technical Congress sponsored by the American Society of Mechanical Engineers, Munich, Germany, May 8-11, 2000. G. James Van Fossen, NASA Glenn Research Center; and Ronald S. Bunker, General Electric Research and Development Center, P.O. Box 8, K-1, ES119, Schenectady, New York 12301. Responsible person, G. James Van Fossen, organization code 5820, (216) 433-5892.

12a. DISTRIBUTION/AVAILABILITY STATEMENT 12b. DISTRIBUTION CODE

Unclassified - Unlimited

Subject Categories: 07 and 34

Distribution: Nonstandard

This publication is available from the NASA Center for AeroSpace Information, (301) 621-0390.

13. ABSTRACT (Maximum 200 words)

Heat transfer measurements have been made in the stagnation region of a flat plate with a circular leading edge.

Electrically heated aluminum strips placed symmetrically about the leading edge stagnation region were used to measure spanwise averaged heat transfer coefficients. The maximum Reynolds number obtained, based on leading edge diameter, was about 100,000 . The model was immersed in the flow field downstream of an approximately half scale model of a can-type combustor from a low $\mathrm{NO}_{\mathrm{x}}$, ground based power-generating turbine. The tests were conducted with room temperature air; no fuel was added. Room air flowed into the combustor through six vane type fuel/air swirlers. The combustor can contained no dilution holes. The fuel/air swirlers all swirled the incoming airflow in a counter clockwise direction (facing downstream). A 5-hole probe flow field survey in the plane of the model stagnation point showed the flow was one big vortex with flow angles up to $36^{\circ}$ at the outer edges of the rectangular test section. Hot wire measurements showed test section flow had very high levels of turbulence, around 28.5 percent, and had a relatively large axial-length scale-to-leading edge diameter ratio of 0.5 . X-wire measurements showed the turbulence to be nearly isotropic. Stagnation heat transfer augmentation over laminar levels was around 77 percent and was about 14 percent higher than predicted by a previously developed correlation for isotropic grid generated turbulence.

\section{SUBJECT TERMS}

Heat transfer; Gas turbine; Turbulence

15. NUMBER OF PAGES

14

16. PRICE CODE $\mathrm{AO3}$

\begin{tabular}{|c|c|c|}
\hline $\begin{array}{c}\text { 17. SECURITY CLASSIFICATION } \\
\text { OF REPORT } \\
\text { Unclassified }\end{array}$ & $\begin{array}{c}\text { 18. SECURITY CLASSIFICATION } \\
\text { OF THIS PAGE } \\
\text { Unclassified }\end{array}$ & $\begin{array}{c}\text { 19. SECURITY CLASSIFICATION } \\
\text { OF ABSTRACT } \\
\text { Unclassified }\end{array}$ \\
\hline
\end{tabular}

NSN 7540-01-280-5500

Standard Form 298 (Rev. 2-89)

Prescribed by ANSI Std. Z39-18 298-102 